\title{
Processos enunciativos e identidade semântica da preposição por
}

Márcia Romero

Submetido em 14 de novembro de 2012.

Aceito para publicação em 01 de abril de 2013.

Cadernos do IL, Porto Alegre, n. ${ }^{\circ}$ 46, junho de 2013. p. 149-170.

\section{POLÍTICA DE DIREITO AUTORAL}

Autores que publicam nesta revista concordam com os seguintes termos:

(a) Os autores mantêm os direitos autorais e concedem à revista o direito de primeira publicação, com o trabalho simultaneamente licenciado sob a Creative Commons Attribution License, permitindo o compartilhamento do trabalho com reconhecimento da autoria do trabalho e publicação inicial nesta revista.

(b) Os autores têm autorização para assumir contratos adicionais separadamente, para distribuição não exclusiva da versão do trabalho publicada nesta revista (ex.: publicar em repositório institucional ou como capítulo de livro), com reconhecimento de autoria e publicação inicial nesta revista.

(c) Os autores têm permissão e são estimulados a publicar e distribuir seu trabalho online (ex.: em repositórios institucionais ou na sua página pessoal) a qualquer ponto antes ou durante o processo editorial, já que isso pode gerar alterações produtivas, bem como aumentar o impacto e a citação do trabalho publicado.

(d) Os autores estão conscientes de que a revista não se responsabiliza pela solicitação ou pelo pagamento de direitos autorais referentes às imagens incorporadas ao artigo. A obtenção de autorização para a publicação de imagens, de autoria do próprio autor do artigo ou de terceiros, é de responsabilidade do autor. Por esta razão, para todos os artigos que contenham imagens, o autor deve ter uma autorização do uso da imagem, sem qualquer ônus financeiro para os Cadernos do IL.

\section{POLÍTICA DE ACESSO LIVRE}

Esta revista oferece acesso livre imediato ao seu conteúdo, seguindo o princípio de que disponibilizar gratuitamente o conhecimento científico ao público proporciona sua democratização.

http://seer.ufrgs.br/cadernosdoil/index

Sexta-feira, 14 de junho de 2013 


\title{
PROCESSOS ENUNCIATIVOS E IDENTIDADE SEMÂNTICA DA PREPOSIÇÃO POR
}

Márcia Romero ${ }^{1}$

\begin{abstract}
RESUMO: Este artigo busca contribuir para o estudo da riqueza de usos característicos da preposição POR no português do Brasil pelo viés de uma abordagem unitária, no que se refere ao seu funcionamento como unidade linguística. Serão analisadas suas contribuições semânticas para a produção do sentido dos enunciados por meio do papel que a preposição exerce nas diferentes construções nas quais aparece. Após apresentar os desafios envolvendo uma proposta de caracterização capaz de dar conta da identidade semântica de POR, propomos uma análise inspirada nos trabalhos desenvolvidos por Franckel e Paillard (2007), cujos objetivos são o de reconstituir o que há de comum entre os diferentes usos e compreender o modo como se estabelece a variação.
\end{abstract}

PALAVRAS-CHAVE: semântica preposicional; português brasileiro; identidade semântica.

\section{CONSIDERAÇÕES INICIAIS}

Fundamentado no referencial teórico-metodológico desenvolvido pela Teoria das Operações Enunciativas e, no âmbito da semântica preposicional, nos trabalhos de Franckel e Paillard (2007), este trabalho apresenta um formato de descrição unitário da preposição POR no português do Brasil que, sustentado por um esquema operatório de natureza enunciativa, contribui para compreender a variação semântica constitutiva de seu funcionamento nos diferentes usos que dela são feitos. Mais especificamente, nosso propósito consiste em analisar o modo como esse formato de descrição unitário, concebido como a identidade semântica da preposição, regula e organiza a constituição dos enunciados.

Vale notar que estimular a observação de situações de uso da unidade linguística que se busca analisar, evidenciando os valores semânticos por ela adquiridos nesses usos, é de grande valia para que uma postura reflexiva sobre os fatos da língua seja efetivada. Essa postura, no entanto, pelo que vimos observando, entra em confronto com a sistematização inerente à descrição linguística. De que maneira conduzir o raciocínio analítico e reflexivo se, diante dos fenômenos observados nos usos da língua, raramente as definições conferidas à unidade linguística a ser analisada, quando existem, se sustentam? Como conciliar o trabalho com os usos linguísticos e a descrição do modo de funcionamento linguístico?

1 Doutorado em Letras pela Universidade de São Paulo (USP). Professora do Departamento de Educação, Área de Língua Portuguesa da Universidade Federal de São Paulo. E-mail: marcia.romero@unifesp.br 
Esse questionamento perpassa a análise do funcionamento da preposição POR no português do Brasil ${ }^{2}$, pelos motivos que serão expostos a seguir.

Sob a ótica da gramática tradicional, a preposição tem sido descrita como um relator, como o que relaciona termos, qualificativo este que consideramos vago por dois motivos de natureza distinta: pela forma como é concebido o significado atribuído às preposições em seus diferentes empregos e pela definição dada aos termos relacionados, comumente apreendidos, no âmbito da oração, como antecedente (termo que antecede a preposição) e consequente (termo que a segue). Decorre destas colocações um problema fundamental para a compreensão do funcionamento linguístico da preposição, que atinge, como veremos a seguir, a própria especificação da relação semântica inerente à preposição analisada e a delimitação do que vem a ser o antecedente na oração ${ }^{3}$.

Essa questão, embora receba um tratamento diferenciado na Gramática de usos do português (NEVES, 2000), de vertente funcionalista, e, mais recentemente, na Gramática do português culto falado no Brasil: classes de palavras e processos de construção (ILARI \& NEVES, 2008), de vertente funcionalista-cognitivista, ainda carece de estudos que contribuam para o desenvolvimento dos estados atuais dos trabalhos, por não ser fornecido um formato de descrição unitário da preposição que responda pela variação observada em seu próprio uso ou por se deixar de fora, nas explicações, um certo número de usos.

Com efeito, em Neves (2000, p. 18), se a preposição "tira seu valor das relações contraídas entre os elementos cuja junção ela efetua" e se "avaliam-se, na descrição do uso da preposição: a) o seu significado unitário; a natureza dos dois termos em relação; a relação sintática entre o antecedente e o consequiente; os traços semânticos dos dois termos em relação e a relação semântica que entre eles se estabelece", não são explicitados, nas análises, o que se entende por significado unitário da preposição, nem de que maneira esse significado unitário contribui para a construção da relação semântica estabelecida.

Assim, em relação à discussão direcionada à preposição POR, para fornecer apenas alguns exemplos trazidos por Neves (2000), observam-se descrições em que a preposição ora funciona no sistema de transitividade, introduzindo complemento de verbo, de adjetivo e de substantivo, ora funciona fora do sistema de transitividade, estabelecendo relações semânticas nos diferentes sintagmas.

Examinando especificamente alguns dos exemplos em que a preposição funciona no sistema de transitividade e introduz complemento de verbo, temos complementos que se referem ao objeto da ação com verbos que indicam "cuidado, zelo": Olhe POR ela; Ainda bem que tinha parentes zelando POR ti (p. 701, grifos do autor); complementos que se referem ao objeto de referência com verbos que indicam orientação, norteamento: Sempre me guiei POR esse pensamento e é dessa forma que conduzo minha vida profissional (p. 702, grifos do

\footnotetext{
2 Esse estudo está inserido em um projeto de pesquisa mais amplo, coordenado por Romero e intitulado Gramática operatória, enunciação e ensino de línguas: sistematização do funcionamento verbal (2008). São frutos deste projeto os trabalhos de Romero (2011), Romero e Vilela (no prelo), este último decorrente de comunicação feita no Seminário Enunciação e materialidade linguística (UFMG, junho 2012), trabalhos que este artigo retoma e desenvolve. Esses trabalhos, em seus fundamentos, devem - e muito - às valiosas discussões que tivemos com o Prof. Denis Paillard, a quem deixamos expressa toda a nossa gratidão.

3 Para uma discussão detalhada sobre a definição do antecedente, ver Franckel; Paillard (1997, 2006 e 2007).
} 
autor); complementos que se referem ao beneficiário da ação verbal, com verbos que indicam empenho, esforço: No final, disse que rezaria POR mim (p. 703, grifos do autor), etc.

Esses exemplos são suficientes para que se perceba que nada é dito a respeito do significado da preposição e de como ele interage com os outros termos da oração. Aponta-se, exclusivamente, para o que seria o "sentido" dos verbos (olhar e zelar como verbos que, nesses contextos, indicam cuidado, zelo; guiar como verbo que indica orientação, norteamento; rezar como verbo que indica empenho, esforço) e para os papéis dos complementos (objeto da ação, objeto de referência, beneficiário da ação verbal), o que nos conduz a interpretar a preposição como um relator dessemantizado, sem sentido. Some-se a isso o fato de o próprio critério de classificação dar margens a outras leituras, pois por que não interpretar No final, disse que rezaria POR mim como indicando zelo, ou não interpretar Olhe POR ela como indicando empenho, sendo ela o beneficiário da ação verbal?

Em relação à delimitação do antecedente, nos empregos em que a preposição introduz complemento, a frequente associação do termo antecedente ao verbo ou ao termo que é complementado, por serem estes que regem o argumento, se aparentemente resolve a questão, traz outra grave consequência para o estudo do tema, visto a relação entre o antecedente $\mathrm{X}$ e o consequente $\mathrm{Y}$ deixar de ser apreendida como uma relação em que $\mathrm{Y}$ determina $X$, relação que, ao contrário, se observa nos empregos em que a preposição funciona fora do sistema de transitividade ${ }^{4}$, introduzindo adjuntos.

Por meio desses dois tipos de funcionamento das preposições, um vinculado ao sistema de transitividade, outro no qual a preposição se encontra fora dele, as descrições estabelecem, de saída, uma cisão no que se refere à semântica preposicional, impossibilitando a busca de uma descrição que responda à variedade de seus empregos independentemente das categorizações sintáticas que concebem o termo introduzido pela preposição como complemento (no sistema de transitividade) ou adjunto (fora do sistema de transitividade).

O estudo de Neves (2000), embora forneça uma descrição detalhada dos inúmeros empregos da preposição, não propicia reflexões que permitam compreender essa proliferação de usos, sobretudo pelo fato de propor uma sistematização atrelada à descrição dos contextos de ocorrência sem que a contribuição semântica de POR para a construção de tais contextos seja, de fato, especificada.

Por mais que o estudo não tenha uma finalidade classificatória, não se escapa, por fim, da formação de listas segundo as variadas funções e usos que a preposição pode ocupar nos enunciados. Ressaltemos ainda que, nos casos em que POR funciona fora do sistema de transitividade, os valores semânticos que lhe são atribuídos parecem muito mais vinculados aos termos que a cercam do que algo que intrinsecamente lhes diz respeito, como vemos nos exemplos (a) Amarraram uns aos outros com cipós e com o auxílio do burrinho Maracujá, os arrastaram PELO campo até a hortinha (p. 704, grifos do autor) e (b) Tico apeou, agarrou-o PELAS orelhas e tentou arrastá-lo (p. 705, grifos do autor), em que, em (a), com verbo de movimento, POR indica percurso, em (b), com verbo de ação que indica apreensão, POR refere-se ao ponto de contato.

4 Como assinalam Franckel e Paillard (2006, p. 7-19), considerar, nos casos de transitividade (ou recção verbal), que o complemento ou $\mathrm{Y}$ estaria na origem da determinação de $\mathrm{X}$ entra em confronto com o estatuto de termo dependente, cujo regente é o verbo. 
Tais colocações vão ao encontro das observações feitas por Ilari e Neves (2008), que afirmam justamente que:

\begin{abstract}
Uma das falhas das abordagens tradicionais da preposição é a dificuldade de fornecer um tratamento abrangente para cada uma delas, que não se traduza em uma enumeração interminável dos "sentidos" que a preposição assume em seus diferentes usos e contextos. As afirmações a que leva esse tipo de tratamento não são propriamente erradas, mas são, no mais das vezes, óbvias, e tendem a transferir para a preposição elementos de sentido que, de fato, são dados por outras expressões presentes no contexto. (ILARI; NEVES, 2008, p. 626)
\end{abstract}

Se o tratamento que Neves (2000) confere às preposições não pode ser considerado tradicional, nem por isso escapa à parte das críticas que cabem a essas abordagens, e tanto essa afirmação é válida que, oito anos depois, esse tratamento adquire outros contornos em Ilari e Neves (2008).

Tendo por objetivo tratar da variedade de sentidos que cada preposição assume em seus diferentes empregos na perspectiva da continuidade (ILARI; NEVES, 2008), os autores assumem a polissemia como uma de suas características constitutivas e defendem que alguns dos sentidos observados devem ser considerados como extensões de um sentido primeiro que lhe seria próprio, como atestam Ilari e Neves (2008, p. 653): "Nas extensões polissêmicas, há sempre resquícios dos usos originários, e são esses usos que justificam as extensões de sentido, mesmo que o falante não os perceba."

No enfoque cognitivista, referencial teórico adotado pelos colaboradores responsáveis pelo capítulo direcionado às preposições (ILARI; NEVES, 2008), esse sentido original é necessariamente vinculado ao espaço.

Com efeito, para o cognitivismo, a linguagem, formatada pela cognição humana, "busca recursos nas percepções características da espécie (a visão e a audição do ser humano são diferentes das dos cães, por exemplo), nas experiências motoras básicas [...] (por exemplo, de deslocamento no espaço, de transferência e de aproximação de objetos, de superação de obstáculos etc.) e nas experiências culturais" (ILARI; NEVES, 2008, p. 648). As experiências motoras motivariam os esquemas imagéticos de natureza espacial atribuídos às preposições, "esquemas muito gerais, desprovidos de conteúdo proposicional e de formulação linguística, e vinculados diretamente à percepção de si próprio e do ambiente" (ILARI; NEVES, 2008, p. 649). A prioridade cognitiva dada ao espaço, segundo os autores, é justificada pelo fato de este ser uma experiência humana primordial, na qual convergem "a percepção da capacidade de movimento corporal e a percepção das coisas que rodeiam o ser humano como entidades únicas” (ILARI; NEVES, 2008, p. 650).

Em suma, nessa perspectiva teórica, a preposição traz esquemas espaciais como sentido de base, podendo se verificar transposição de esquemas em relação a outros sentidos, i.e. a conceitualização de objetos e situações de um determinado tipo em termos de outros objetos e situação (empregos também conhecidos por uso metafórico das preposições).

No caso de POR, os autores entendem que um de seus usos prototípicos é "aquele que aponta, no decorrer do trajeto, um espaço de passagem” (ILARI; NEVES, 2008, p. 
752) $)^{5}$. Também se emprega o termo deslocamento para caracterizá-la, sendo focalizados nessa caracterização os pontos intermediários entre a origem e a chegada do deslocamento. Um exemplo de transposição de esquemas seria a aplicação da organização espacial trazida pela preposição para o domínio temporal, como mostra o exemplo "os presidentes são eleitos por um período de três anos" (ILARI; NEVES, 2008, p. 677), em que da noção de percurso através - este, um dos sentidos de base da preposição POR - deriva a noção de duração.

No que se refere à delimitação do antecedente, no processo de complementação, quem seleciona a preposição é a palavra ou sintagma a ser completado, enquanto que no processo de adjunção, a escolha da preposição depende da natureza do adjunto. Não se observam, portanto, diferenças em relação a Neves (2000), visto que as duas formas de determinação que agem na dimensão linear da sentença permanecem: uma na qual $\mathrm{X}$, termo antecedente, localiza o consequente Y (complementação), outra na qual se observa uma relação de localização de $\mathrm{X}$ por $\mathrm{Y}$ (adjunção). Tal cisão aponta para a gramaticalização da preposição, ou seja, para a possibilidade de a preposição, nas palavras dos autores, "realizar tarefas' mais tipicamente gramaticais, como introduzir argumentos dos verbos" (ILARI; NEVES, 2008, p. 633).

A tentativa de compreender de forma unificada os vários usos de uma mesma preposição consiste, sem dúvida, no ponto forte das análises. Ainda assim, restam empregos que, por não serem concebidos como extensões de sentido, são denominados resíduos ${ }^{6}$; mas, sobretudo, restam empregos sequer mencionados pelo fato de serem sintaticamente insignificantes, como os de POR introduzindo predicativos (Ele passou por um fraco; Ele me tomou por médico, etc.), um de seus empregos mais instigantes.

Há, portanto, três grandes questões envolvidas no estudo da semântica preposicional e que, apresentadas de modo pontual, dizem respeito à identidade semântica da preposição, ao modo como essa identidade contribui para a produção de sentidos nos enunciados e à relação entre Y (termo consequente, independentemente da categorização sintática que lhe é atribuída) e o termo X, antecedente a ser definido.

Em uma posição alternativa às mencionadas, nosso trabalho busca responder às questões introduzidas sustentando que: em relação à natureza semântica de POR, embora postulemos um formato de descrição unitário, este não se apresenta como a tradução de um sentido existente fora da própria materialidade linguística na qual a preposição se encontra inserida, o que atesta a impossibilidade de identificá-la, semanticamente, por meio de um sentido primeiro dos quais outros decorreriam por extensão; em relação à natureza sintática das relações estabelecidas pela preposição, o pertencimento ou não ao sistema de transitividade não interfere no formato de descrição unitário; por fim, a caracterização da preposição como o que institui a relação entre dois termos X e Y não basta para que se compreenda o seu papel nas interações constitutivas do sentido dos enunciados aos quais se

5 Encontramos o seguinte comentário a respeito desta preposição: "É uma preposição frequente e dotada de alto grau de gramaticalização; é uma das tantas que se explicam pela noção de trajeto, marcando relações de espaço, tempo e agente." (ILARI; NEVES, 2008, p. 664).

6 Segundo os autores, tais empregos - que, como veremos adiante, são conhecidos por usos concessivos ou de causa discursiva - "fazem intervir outros aspectos da estrutura linguística além dos estritamente locativos, de modo que os esquemas estritamente locativos não dão para eles uma explicação completa" (ILARI; NEVES, 2008, p. 759). Além disso, há, nos resíduos, usos considerados como próximos de "um automatismo gramatical que talvez escape de uma explicação estritamente cognitiva” (ILARI; NEVES, 2008, p. 759). 
integra. Na sequência do texto, analisaremos quais as contribuições de POR para a produção do sentido dos enunciados, detendo-nos, particularmente, no estatuto dos termos $\mathrm{X}$ e Y postos em relação pela preposição.

\section{ALGUNS USOS REPRESENTATIVOS DE POR NO PORTUGUÊS DO BRASIL}

Ao descrever a preposição POR como um relator $\mathrm{R}$ instituindo a relação entre $\mathrm{X}$ e $\mathrm{Y}$, se a caracterização de $\mathrm{Y}$ como termo que segue a preposição (consequente) não é questionada, $\mathrm{X}$, apreendido como antecedente, não é um termo necessariamente evidente na relação, nem se encontra explícito nos diferentes enunciados aos quais POR se integra e ajuda a construir. Na concepção de relator adotada neste trabalho, confere-se ao antecedente um estatuto não simétrico em relação a Y.

Encontramos em Franckel e Paillard (2007, p. 13-14) o fundamento desse estatuto conferido à noção de relator:

Guardaremos a idéia já evocada, e formulada por numerosos autores, de que uma preposição é um relator (no âmbito de um esquema $\mathbf{X} \mathbf{R}$ (prep) $\mathbf{Y}$ ), a questão sendo a de determinar o que relaciona. Pode-se dizer que ela coloca em relação dois elementos $\mathbf{X}$ e $\mathbf{Y}$, constituindo uma relação não simétrica na qual $\mathbf{Y}$ adquire a função de orientador de $\mathbf{X}$. Enquanto orientador, $\mathbf{Y}$ é fonte de determinação para $\mathbf{X}$. Se a identificação do termo correspondente a $\mathbf{Y}$ não traz problemas a priori (trata-se do termo que segue a preposição), isto não se observa com o termo $\mathbf{X}$. Este só aparece claramente identificável em certos empregos de localização espacial: le livre dans le tiroir, la mouche sur le plafond. Mas uma dificuldade crucial aparece nos casos dos empregos "funcionais" da preposição, em que o sintagma preposicional é analisado como "complemento argumental" do verbo: tirer sur les rideaux; hésiter entre plusieurs options; cette pièce donne dans le couloir. Parece que para a maioria dos autores, $\mathbf{X}$ corresponde então ao próprio verbo, posição que veremos ser difícil de sustentar, a começar pela contradição que a função de $\mathbf{Y}$ como orientador implica. De um modo geral, a descrição das preposições privilegia frequentemente a preposição em si e o termo correspondente a $\mathbf{Y}$ (como testemunha a própria terminologia de "complementos preposicionais" ou ainda "sintagmas preposicionais"). Por simples comodidade, conservaremos esta terminologia, sem deixar de evidenciar o problema central da identificação do que corresponde a $\mathbf{X}$ no esquema $\mathbf{X} \mathbf{R}$ Y (FRANCKEL; PAILLARD, 2007, p. 13-14, tradução nossa).

Essas colocações serão retomadas na continuidade do texto, mas já fundamentam esta primeira análise de alguns dos usos característicos de POR, cujas construções evidenciam três grupos, segundo a natureza de $\mathrm{X}^{7}$ :

I. Empregos intraproposicionais, em que $X$ é um termo constitutivo de uma relação predicativa;

7 Os exemplos constam, em sua grande maioria, do corpus fornecido por Neves (2000). As análises apresentadas retomam Romero (2011) e Romero e Vilela (no prelo) a partir de novos desenvolvimentos, parte deles oriundos das reflexões trazidas por Paillard (no prelo). 
II. Empregos sintagmáticos, em que X é um sintagma nominal formando com Y um sintagma nominal complexo;

III. Empregos interproposicionais, em que X é uma proposição.

As análises apresentadas estão longe de esgotar os usos desta preposição no português do Brasil. No entanto, ao selecionar exemplos representativos de seus empregos, o que se busca, por ora, é chegar a uma inteligibilidade explicitável do funcionamento enunciativo de POR tomando a glosa por princípio metodológico de observação.

A glosa apresenta-se como um procedimento de formalização da linguagem por si mesma. Fundamentada em um trabalho de abstração, a glosa consiste em uma prática de reformulação em que o "acesso à identidade de uma unidade pode ser constituído pela análise metodologicamente controlada do papel que ela desempenha nos enunciados em que é colocada em jogo" (DE VOGÜÉ et al., 2011, p. 119). Como bem explica Franckel (DE VOGÜÉ et al., 2011, p. 122), a glosa propõe "uma análise que não seja uma simples reformulação local e conjuntural [de um dado exemplo], mas uma reformulação que comporte os princípios de um reinvestimento possível na descrição de outros exemplos", e, aqui, acrescentamos, em que POR se faça presente. Isso justifica, de um lado, a nossa opção por, quando der, apresentar os empregos em contextos discriminativos, em que a preposição é ou não observada, de outro, o procedimento detalhista da análise, cujo propósito é dar a ver os limites enunciativos impostos pela própria unidade e que são característicos de seu funcionamento.

$\mathrm{Na}$ sequência, os exemplos serão inicialmente discutidos tomando como ponto de partida o grupo do qual fazem parte. Os exemplos que integram o grupo III serão discutidos posteriormente, após a discussão envolvendo a identidade semântica de POR.

2.1. Empregos intraproposicionais - POR introduz $Y$ que recai sobre $X$, termo constitutivo de uma relação predicativa.

\section{(1') Optei.}

A relação predicativa construída por optar implica necessariamente uma opção não especificada ou explicitada (termo X). No exemplo (1'), coloca-se que a opção foi feita, sem dizer de qual opção se trata (ela não é especificada). Já em (1), o SN a luta imediata, termo Y introduzido por POR, torna visível X, ou seja, a opção feita, ao lhe conferir uma determinação específica. Ao fazê-lo, constrói-se, simultaneamente, um sujeito engajado na luta imediata ${ }^{8}$.

\section{Chama POR Padim Ciço.}

8 Como veremos na sequência do texto, esse efeito de engajamento aparece em muitos exemplos construídos com POR, como é o caso de Valorize o seu voto. Vote pela sua cidade. Vote limpo, mote da campanha eleitoral de 2012, assinada pelo Tribunal Superior Eleitoral. 
Nestes exemplos, chamar remete a um comportamento verbal dirigido a um interlocutor. Em (2), o comportamento verbal (o chamado, que notamos X) é motivado por Y, visto ser Padim Ciço o que condiciona e determina as palavras que lhes são dirigidas. Se há chamado, é por existir, antes, Padim Ciço a quem esse chamado se dirige. Já, em (2'), o chamado apenas confere existência a Padim Ciço: ao ser chamado, Padim Ciço, antes ausente, torna-se verbalmente presente para o locutor. Temos, assim, em (2) e (2'), duas relações diferentes: uma em que o chamado é construído pelo verbo, mas é a preposição que introduz o termo condicionando tal chamado; outra em que é o próprio chamar que constrói e especifica o que é chamado. Isso explica as aproximações semânticas observadas. Chamar, em (2), aproxima-se de rogar/suplicar, o que mostra existir alguém a quem a súplica é dirigida; ainda em (2), Padim Ciço (Y) interpreta-se como um santo ${ }^{9}$. Em (2'), chamar aproxima-se de atrair a atenção de alguém, o que mostra que o objetivo é torná-lo presente no espaço interlocutivo. Padim Ciço, nesse caso, tende a ser interpretado como uma pessoa qualquer.

$$
\text { O vai-e-vem da moça vale POR } 100 \text { garrafas de catuaba. }
$$

O vai-e-vem da moça vale 100 garrafas de catuaba.

Em (3'), o vai-e-vem da moça é mensurado como valendo 100 garrafas de catuaba. Este termo diz o valor a ser pago, instituindo uma relação em que há algo a ser trocado ( $o$ vai-e-vem da moça) por outro elemento cujo preço é equivalente: 100 garrafas de catuaba. Em (3), valer não se resume à idéia de troca: não se paga o vai-e-vem da moça com 100 garrafas de catuaba. O que se diz é que, ao invés de se beber 100 garrafas de catuaba, basta experimentar o vai-e-vem da moça, de modo que o efeito atribuído a 100 garrafas de catuaba (termo Y) determina o valor do efeito produzido por o vai-e-vem da moça. Em suma, se em (3') temos, antes, o vai-e-vem da moça e, depois, lhe atribuímos um valor, em (3), já se parte do fato de o vai-e-vem apresentar um valor/efeito não especificado (termo $\mathrm{X})$. Y confere uma determinação particular ao efeito do qual se parte, por ser o que permite apreender o que $o$ vai-e-vem é capaz de proporcionar.

O escritório foi organizado PELO Maurício Clark.

Parte-se, aqui, de um escritório organizado, visto organizado marcar a predicação sobre o sujeito sintático de um estado (resultante). Há, portanto, um argumento origem da organização (termo X), mesmo se, no plano sintático, este argumento tenha sido colocado em outro plano (emprego dito passivo). Y reintroduz esse argumento, conferindo-lhe uma visibilidade a posteriori.

Passamos POR Porto Seguro.

Passamos Porto Seguro.

9 Diz-se, justamente, Chama POR Deus. 
Observa-se, novamente, que a construção preposicional interfere na semântica do verbo. Em (5'), Porto Seguro remete a um ponto de referência entre outros em relação ao qual a trajetória construída por passar é vista como ininterrupta: se poderíamos ter parado em Porto Seguro, não o fizemos. Passar evoca o que passa, o que não para, visto a transicionalidade do processo recair exclusivamente sobre nós (Porto Seguro exprime o ponto em que a trajetória poderia ter sido interrompida, não sendo abarcado como lugar de passagem). Em (5), a transicionalidade do processo recai ao mesmo tempo sobre nós e Porto Seguro: nós passamos e Porto Seguro serve de lugar de passagem, já que passar evoca uma trajetória com um ponto de partida A e um ponto de chegada B. Ir de A a B constrói uma classe de pontos intermediários possíveis não determinados (X) e Y, Porto Seguro, determina um desses pontos. O processo de passar manifesta-se graças a $\mathrm{Y}$.

Ficou mudo, espiando as três galinhas, que ciscam POR ali.

(6') Ficou mudo, espiando as três galinhas, que ciscam ali.

Em (6'), a ausência de POR confere à situação descrita uma precisão espacial não encontrada em (6): em (6'), ali indica um lugar específico onde as galinhas ciscam; já em (6), o que é ciscado encontra-se em um dado lugar: ali não remete, portanto, a um lugar preciso, mas ao espaço onde está o que é ciscado. Assim, em (6'), ali seleciona um elemento entre outros da classe de lugares onde se pode ciscar: é ali, e não aqui ou no jardim. Nesse exemplo, ali não remete a uma extensão espacial, por ser apreendido como um elemento entre outros da classe de lugares para ciscar. Por sua vez, em (6), ali não remete a um elemento entre outros da classe de lugares: ele constitui, por si só, um lugar singular, embora impreciso, e adquire uma espessura que não teria se não estivesse vinculado a POR. Ciscar evoca um lugar não determinado (X) que é especificado por ali (Y). Esta especificação, ao colocar que o ciscar se desenrola exatamente nessa extensão espacial definida por ali, constroi, ao mesmo tempo, uma idéia de imprecisão, colocando em evidência, sobretudo, o processo de ciscar. Por fim, se em (6'), evidencia-se o lugar em que as galinhas ciscam, em (6), evidencia-se o processo de ciscar em um dado lugar.

Já estava viciado, bebia cinco copos POR dia.

Ele bebeu cinco copos.

Em (7'), cinco copos apreende a quantidade de líquido bebido, que é definida pela própria ocorrência do processo beber. Já em (7), cinco copos, embora objeto do processo "ele bebia (7)", é determinado não como uma quantidade em si, mas como uma quantidade definida em relação a um intervalo de tempo: dia (Y). Ao associar a quantidade bebida a um intervalo de tempo, $P O R$ a dissocia do próprio processo, de modo que não se tem mais a quantidade definida por uma ocorrência de beber ( $\mathrm{X}$ diz respeito a uma quantidade não especificada inicialmente, por não estar mais relacionada ao processo de beber). Daí a ideia de repetição. 
2.2. Empregos sintagmáticos - POR introduz um sintagma operando sobre um sintagma nominal complexo.

Se falamos em sintagma nominal complexo, é pelo fato de $\mathrm{Y}$ requalificar o modo pelo qual a relação entre o verbo e seu complemento é estabelecida. Em um exemplo como (8) Eu verifiquei a conta número POR número, abaixo analisado, POR Y redefine o que vem a ser a própria verificação da conta. São construções em que $\mathrm{X}$ e $\mathrm{Y}$, aparentemente, são duas ocorrências do mesmo N: número POR número, parede POR parede, menino POR menino etc.

(8) Eu verifiquei a conta número POR número.

(8') Eu verifiquei a conta.

Ao compararmos os exemplos, vemos que em (8'), a conta não é vista como uma soma de quantidades ou de diferentes elementos numéricos. Em outras palavras, a verificação incide sobre a conta, apreendida sem qualquer forma de detalhamento. Já em (8), número por número redefine o termo conta como um conjunto de números em que cada número é objeto de uma verificação. Dada a existência de um número concebido como elemento de um todo - de uma soma - POR Y determina cada número como aquele sobre o qual recai a verificação (considera-se número no âmbito de uma verificação). Em número1 POR número2, Y [número2] retoma [número1] e o dissocia da adição para the conferir uma visibilidade própria. Ressaltemos que em Eu pintei o quarto parede POR parede, reencontramos o mesmo mecanismo ora descrito: não se pinta o quarto em si, mas cada parede, uma após a outra, conferindo-se ao termo parede uma existência independente do quarto do qual faz parte.

\subsection{Primeiras considerações}

Como já observamos, longe de ser exaustivo, esse estudo inicial a partir de contextos discriminativos teve por objetivo propiciar uma primeira aproximação do papel da POR no funcionamento enunciativo de diferentes exemplos, independentemente de estar a preposição associada a processos de complementação ou de adjunção.

O estudo permite ainda retomar casos como (9) O consumidor está comprando gato POR lebre ou (10) Olho POR olho, dente POR dente, usos que, tidos como idiomáticos, ficam comumente de fora das análises.

Nessa retomada, nota-se que é possível explicar o raciocínio trazido à tona em (9) da seguinte maneira: embora se espere receber algo equivalente ao que efetivamente foi gasto, o que se recebe é algo "maquiado", que passa pelo que não é. Assim, o termo lebre (Y) requalifica o valor que a compra atribui ao termo gato (X é o valor que gato adquire por meio da compra), conferindo-lhe um valor que este não possui por si só. O que se tem, por fim, é o valor de gato apreendido sob a ótica do valor que lebre lhe atribui, sendo esse pseudovalor que orienta a compra. 
Do mesmo modo, em (10) Olho POR olho, percebe-se que, mais do que uma substituição ou troca entre elementos equivalentes, o que se tem é, graças a POR, um mecanismo deveras sutil. Com efeito, da mesma forma que em (9) Comprar gato POR lebre, lebre apreende gato sob a ótica do valor que lebre lhe confere, em (10) Olho POR olho, atribui-se um efeito a POR olho e é esse efeito que vale, por ser ele que diz como o outro olho será apreendido. Em suma, a interpretação não passa pela representação de que "se receber um olho, dá um olho", mas, sim, pelo fato de olho, em POR olho, evocar que algo foi causado, provocado (dele, surtiu um efeito). O que foi provocado servirá de parâmetro para considerar a relação. Mais do que uma troca, o que se representa é uma relação de proporção: o efeito decorrente de um diz necessariamente o modo como o outro será apreendido. O mesmo vale para dente POR dente.

Vejamos, agora mais detalhadamente, como formalizar o funcionamento característico da identidade semântica de POR.

\section{UMA PROPOSTA DE FORMALIZAÇÃO}

Alinhado às reflexões propostas por Franckel e Paillard (2007), nosso trabalho fundamenta-se em uma hipótese central: cada preposição tem uma identidade caracterizada em termos de um esquema operatório capaz de descrever o papel desta unidade nas interações constitutivas do sentido dos enunciados aos quais se integra. Segundo os autores, há duas classes de preposição, estruturadas em função da natureza das determinações que $\mathrm{Y}$, termo introduzido pela preposição, confere a X:

A. Preposição de tipo divisão: Y é um domínio estruturado em diferentes zonas (interior, exterior, fronteira) e determinar $\mathrm{X}$ consiste em estabelecer seu vínculo a uma zona do domínio de $\mathrm{Y}^{10}$;

B. Preposição de tipo discernimento: $\mathrm{Y}$, propriedade acidental predicada de $\mathrm{X}^{11}$, constitui um modo de apreensão de X (Y categoriza X). De um modo geral, X é associado a uma predicação e $\mathrm{Y}$ especifica o modo de implicação de $\mathrm{X}$ na própria predicação $^{12}$.

No caso de POR, teríamos, portanto, uma preposição de discernimento.

Para entender a descrição proposta, vale dizer, antes, que um dos postulados constitutivos da Teoria das Operações Enunciativas (DE VOGÜÉ et al., 2011) coloca que não se pode descrever uma unidade independentemente das relações que a constituem. Para dar conta dessas relações, o quadro teórico postula um operador fundamental: $\underline{\epsilon}$.

No que se refere à preposição POR, isso significa que $X \underline{\Theta} Y$ se lê $X$ é posto em relação com $\mathbf{Y}$ e, mais precisamente, que $\mathbf{X}$ é orientado por $\mathbf{Y}$. Assim, os diferentes

$10 \mathrm{O}$ tomo I da Grammaire des prépositions (FRANCKEL; PAILLARD, 2007) é consagrado a preposições, em língua francesa, dessa natureza.

11 Como observa Paillard (no prelo), esse termo foi retomado de Ascombre (1991): "L'article zéro sous préposition", Langue Française 91, p. 24-39.

12 Encontra-se em elaboração o tomo II da Grammaire des prépositions, consagrado a tais preposições. 
exemplos por nós analisados, independentemente da diversidade de valores adquiridos pela preposição, atestam uma característica em comum:

\begin{abstract}
Dada uma relação predicativa, $P O R$ marca que $Y$ determina um elemento constitutivo desta relação, a saber, $X$. $O$ recurso a $Y$ significa que $X$, embora atualizado no âmbito da relação predicativa, é não determinado ou subdeterminado. As determinações introduzidas por $Y$ preenchem a falta de determinações de $X$ enquanto elemento da relação predicativa.
\end{abstract}

A descrição acima deve ser lida da seguinte maneira:

- X, caracterizado por determinações em aberto, convoca uma classe de determinações possíveis;

- Y é um dos elementos da classe capaz de preencher a falta constitutiva de determinações de $\mathrm{X}$.

Essa caracterização explica o fato de $\mathrm{Y}$ conferir uma determinação a um elemento $\mathrm{X}$ não determinado ou subdeterminado, tornando-o visível sob um modo de apreensão específico. São tais indicações que se encontram figurativizadas por meio do esquema abaixo:

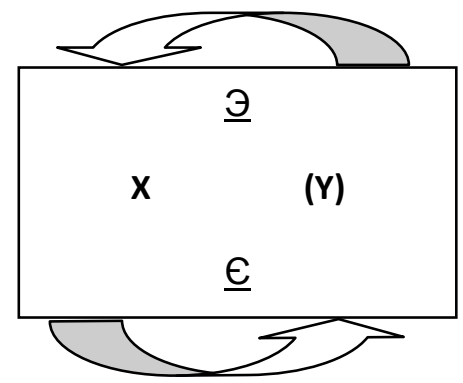

Esse esquema introduz um novo operador $\underline{\exists}$ para marcar a convocação de uma classe de determinações. Desse modo, evidencia-se que a relação de X e Y se dá nos dois sentidos: de um lado, $\mathrm{X}$ não determinado ou subdeterminado convoca uma classe de determinações possíveis (encontramo-nos aquém da seleção de $Y$, daí $\underline{\exists})^{13}$, de outro, Y se apresenta como a determinação selecionada que faz com que $X$ se manifeste sob uma ótica particular, a que lhe atribui o próprio Y (daí $\underline{\epsilon}$ ).

É importante notar que a não determinação ou subdeterminação de $\mathrm{X}$ é um elemento central no esquema operatório constituído, pois é ela que diz como a relação entre $\mathrm{X}$ e $\mathrm{Y}$ se constrói. Se $\mathrm{X}$ não determinado ou subdeterminado solicita determinações, $\mathrm{Y}$ é a determinação que confere a $\mathrm{X}$ o estatuto pleno de termo atualizado da relação predicativa.

Retomemos sucintamente alguns dos exemplos apresentados a fim de melhor compreender o funcionamento descrito:

13 Os parênteses associados a Y designam essa classe de determinações possíveis da qual Y faz parte. 


\section{Optei PELA luta imediata.}

Parte-se aqui de um sujeito que opta e de uma opção cuja determinação (X) se encontra em aberto. Em outras palavras, com optar, a opção é necessariamente feita, mas não realizada por um argumento da relação predicativa. É POR que introduz o termo que determina e dá visibilidade à opção feita, no caso, a luta imediata (Y).

\section{(2) Chama POR Padim Ciço.}

A ausência de objeto do verbo chamar marca a subdeterminação do processo implicando o sujeito. Padim Ciço (Y) confere ao sujeito o estatuto de aquele quem chama ao motivar o chamado: o chamado existe porque, antes, há Padim Ciço. Em outras palavras, temos, na relação predicativa, um chamado (X) sem que haja determinação, da parte do verbo, a quem este chamado se dirige (não há objeto trazido pela relação). Padim Ciço, termo introduzido pela preposição, determina e condiciona esse chamado. Aqui, a determinação vinda do exterior (de Y e não da relação predicativa) leva à perda de autonomia do sujeito, concebendo-o como suplicante.

O vai-e-vem da moça vale POR 100 garrafas de catuaba.

A subdeterminação reside, na relação predicativa construída por valer, na ausência de $\mathrm{N}$ que especifique o valor do vai-e-vem da moça, sendo (X) a referida subdeterminação. O termo 100 garrafas de catuaba (Y) determina de que maneira o vai-e-vem da moça é argumento de valer: por seus efeitos, ele equivale a 100 garrafas de catuaba.

\section{O escritório foi organizado PELO Maurício Clark.}

A subdeterminação $(\mathrm{X})$ deve-se ao fato de a origem do processo não se fazer inicialmente presente. Maurício Clark (Y) torna visível esse argumento a posteriori.

Passamos POR Porto Seguro.

Temos uma trajetória com um ponto de partida A e um ponto de chegada B. Ir de A a B constrói uma classe de pontos intermediários possíveis, mas não especificados $(\mathrm{X})$, já que existem muitas maneiras de ir de A a B. Porto Seguro (Y), ao determinar um desses pontos, especifica a trajetória adotada.

(6) Ficou mudo, espiando as três galinhas, que ciscam POR ali.

Há, na relação predicativa, um lugar não determinado (X) que é especificado por ali (Y). Esta determinação diz que o processo de ciscar se desenrola na extensão espacial definida por ali, o que confere à situação evocada uma idéia de imprecisão. Evidencia-se, por fim, não o lugar onde as galinhas ciscam, mas o fato de haver um ciscar ocorrendo em um dado espaço.

(7) Já estava viciado, bebia cinco copos POR dia. 
Neste caso, o termo cinco copos deixa de determinar a quantidade de líquido bebido (caso, por exemplo, de Ele bebeu cinco copos), para evocar uma quantidade que, por não estar mais relacionada ao processo beber, é vista como não determinada (se cinco copos não esgota o bebido, ao que se relaciona?). O vínculo do processo com um intervalo de tempo (Y) dia significa, portanto, que cinco copos deixa de se constituir como uma ocorrência de beber para ser uma quantidade de líquido bebido especificada por dia.

\section{Eu verifiquei a conta número POR número.}

Em número1 POR número2, Y [número2] retoma [número1] destacando-o da conta da qual fazia parte para lhe conferir uma visibilidade própria. De um número não especificado porque visto como parte de uma conta, ele é apreendido como um número determinado, o número para o qual ele aponta.

\section{SOBRE USOS INTERPROPOSICIONAIS}

Além dos usos acima examinados, há um terceiro grupo em que POR introduz um termo consequente ou faz parte de uma sequência que condiciona a interpretação de uma proposição Q. São exemplos destes usos (11) Falando POR mim, isso é uma porcaria!, (12) É uma gente cheia de vida, POR incrível que possa parecer, (13) POR mais simples que seja o gesto [...], ele tem a ver com o conjunto, (14) E agora, Primo Ribeiro não falou, POR quê?, entre outros. Analisemos cada um deles para ver de que modo tais usos se aproximam dos anteriores no que se refere ao funcionamento de POR.

\section{Falando POR mim, isso é uma porcaria!}

Falando por mim é um marcador discursivo, pois confere um estatuto enunciativo a $\mathrm{Q}$ isso é uma porcaria!. Nesse exemplo, Falando por mim retoma um dito Q e o especifica como sendo o dito de alguém, o que relativiza, por sua vez, o próprio dito: o fato de eu dizer isso não significa que outros vão dizê-lo. Mais precisamente, tem-se POR mim, que confere a falando, forma nominal, o sujeito que falta para atribuir um autor ao dito que esta própria forma nominal retoma, no caso Q. De um dito concebido como a qualificação de um fato (isso é uma porcaria) e cuja origem do dizer resta a ser determinada, passa-se, portanto, a um enunciado que evidencia o autor do dizer: mim.

É uma gente cheia de vida, POR incrível que possa parecer.

(12') É uma gente cheia de vida.

Em (12'), a proposição Q É uma gente cheia de vida é concebida como sendo o caso para o enunciador: Q é, portanto, uma simples asserção. Em (12), tem-se uma proposição P (por incrível que possa parecer) que não suspende a asserção, mas a coloca como sendo o caso mesmo se se espera o contrário, mesmo se a qualifica de inacreditável. Em outras palavras, em (12), recupera-se, inicialmente, uma não determinação em relação à validação esperada (não é possível saber se $\mathrm{Q}$ vai ou não ser validado pelo enunciador) para ser 
colocado que há, sim, validação, mas especificada como algo não esperado, inacreditável. P discerne "Q é o caso" (a asserção) como inacreditável.

POR mais simples que seja o gesto [...], ele tem a ver com o conjunto.

Observa-se, aqui, funcionamento semelhante ao anterior. $\mathrm{P}$ (por mais simples que seja o gesto) constroi uma representação que marca que se está aquém da validação de Q não se sabe se um gesto simples tem ou não a ver com o conjunto - e, ao mesmo tempo, reafirma Q: ele tem a ver com o conjunto, embora a especificidade do gesto seja mantida. Em outras palavras, de uma não determinação primeira, passa-se a uma determinação: $P O R$ discerne o gesto em questão como simples sem, por isso, desconsiderar sua pertença ao conjunto considerado ${ }^{14}$.

\section{E agora, Primo Ribeiro não falou, POR quê?}

Há algo na origem do não falar de Primo Ribeiro que não é determinado, fato que pode ser observado na comparação de (14) com (14') E agora, Primo Ribeiro não falou, em que se tem uma constatação em relação a algo que se esperava e não aconteceu. $P O R$ aponta para esta indeterminação e faz com que se percorra a classe de motivos passíveis de explicar o silêncio, materializando esse motivo por meio de quê. Assim, quê marca uma varredura da classe e a indicação de que há algo que motivou o não falar. Em suma, com POR quê, quê introduz e aponta para a presença do motivo, que se encontra determinado por sua própria indicação, embora este não seja, no entanto, dito.

Observam-se, aqui, usos comumente conhecidos por causa discursiva (exemplo 11), concessivo (exemplos 12 e 13) e causal/explicativo (exemplo 14) que podem ser explicados pela relação estabelecida, graças a POR, com Q. No uso concessivo, POR, em (12) reafirma o dito trazido por $\mathrm{Q}$ ao mesmo tempo em que o discerne como inacreditável, da mesma forma que, em (13), coloca, de um lado, a pertença do gesto ao conjunto, de outro, sua especificidade ao discerni-lo como simples; no de causa discursiva (exemplo 11), é o estatuto enunciativo de Q que está em jogo, uma vez que se confere um autor a asserção que faz com que esta seja igualmente discernida; no causal/explicativo (exemplo 14), qualquer que seja o motivo explicitado, mais do que se determinar uma causa ou uma explicação à proposição $\mathrm{Q}$, o que se tem é uma tomada de posição, por parte do locutor, no que diz respeito às proposições postas em relação. Assim, um exemplo como (15) Primo Ribeiro não falou POR estar com a boca cheia de afta, em que o motivo está visível, mostra, sobretudo, que o locutor, ao estabelecer vínculos entre fatos distintos quanto o de não falar e o de estar com a boca cheia de afta, recupera, para estar com a boca cheia de aftas, representações que sustentam o não falar (estar com a boca cheia de aftas evoca dificuldades de articulação, por exemplo). Por fim, o não falar é apreendido sob a ótica do estar com a boca cheia de aftas, o que mostra ainda que, longe de ser entendido como esconder um segredo, este se aproxima de não proferir nada.

14 É interessante notar que no exemplo Embora o gesto seja simples, ele tem a ver com o conjunto, parte-se da representação de que há um gesto simples que não teria a ver com o conjunto, para, posteriormente, reafirmá-lo como integrado ao conjunto, o que é bem diferente de se estar aquém da validação de $\mathrm{Q}$ tal como explicamos em (13). 
Quanto à caracterização proposta para o funcionamento de POR, vê-se que esta guarda sua identidade, pois recupera, desta vez para $\mathrm{X}$ entendido como a predicação à qual a proposição $\mathrm{Q}$ se refere, uma determinação específica que preenche uma não determinação no que se refere:

- ao estatuto enunciativo de Q: (11);

- $\quad$ ao conteúdo proposicional de Q: (12), (13) e (14);

- ao estatuto enunciativo e ao conteúdo proposicional de Q: $(15)^{15}$.

Vale ainda notar que nem sempre POR introduz uma proposição, caso justamente de (11), mas também de Não, falara aquilo POR brincadeira, de certo.

Nesse exemplo, POR (Y) brincadeira faz com que se evidencie o modo como se deu o falar. Reavalia-se, portanto, seu estatuto enunciativo, uma vez que (Y) requalifica o falar e o falante, apontando para um falar que seria destituído de verdade e para um falante do qual se pode duvidar. Em relação à proposição Falara aquilo, POR vai discerni-la a partir de um modo de falar específico entre outros (falar POR maldade, distração etc.).

\section{UM ASPECTO DA DEFORMABILIDADE SEMÂNTICA DE POR}

Como vimos observando, na medida em que os termos X e Y são a priori distintos, POR reformula a alteridade primeira existente entre eles como uma relação.

Essa relação, no entanto, leva ainda em conta o tipo de determinação introduzida por Y, o que dá origem a um aspecto da deformabilidade semântica de POR, já que a determinação pode ser: (A) qualitativa (QLT), i.e. a própria realidade de $\mathrm{X}$ enquanto elemento da relação predicativa é qualificada por Y (X é um suporte de Y); (B) quantitativa (QNT), em que Y apenas localiza X; ou (C) qualitativa e quantitativa (QLT/QNT), em que $\mathrm{Y}$ localiza X e requalifica o estatuto de X. Essa deformabilidade é evidenciada quando, para uma sequência, várias contextualizações são possíveis, caso de (16) Votei PELO Senhor, em que Y confere uma determinação à escolha que o voto traz, mas, ao fazê-lo, apreende a relação instituída entre o eu/votar de modos distintos, como mostram as contextualizações abaixo:

A. EU é porta-voz de $o$ Senhor (Y). EU vota, seu nome consta no ato de votação, mas o voto representa o de outra pessoa. Se houve ato de votar, $E U$ (que votou) efetivou a escolha de outro (o Senhor) e não a sua. Daí a apreensão de $E U$ como um simples porta-voz: sua escolha não se faz presente. A determinação é qualitativa porque Y

15 Notemos que, em (15), há uma causa especificada e uma tomada de posição do locutor em relação a propriedades a priori distintas: não falar e ter a boca cheia de aftas. Isso pode ser igualmente observado em $O$ jacaré do papo amarelo tem o pescoço cor de enxofre por ser mais bravo do que os jacarés outros, em que POR especifica a causa e a tomada de posição do locutor em relação à cor do jacaré. Essa tomada de posição mostra que à noção cor são atribuídas propriedades que não são comumente por ela evocadas, como a natureza feroz do animal. 
faz de $E U$ um suporte para que o votar se manifeste. O ato de votar não é capaz de apreender quem vota como um verdadeiro eleitor.

B. EU vota sob o nome de outro: o nome que consta no ato de votação é o de outro, sendo que ora $E U$ exerce a sua escolha sob o nome de outro, ora diz a escolha feita por outro. Se $E U$ não é apreendido como porta-voz, é porque sua escolha é efetivada (ainda que por meio do nome de outro) ou porque a escolha de outro aparece sob o nome do outro mediada por mim. A determinação introduzida é quantitativa por haver mera localização do ato de votar, o nome que consta no ato votação impedindo que $E U$ seja visto, uma vez mais, como eleitor.

C. Houve uma escolha feita por $E U$, e $o$ Senhor diz quem foi o escolhido e condiciona o fato de ter havido escolha. $O$ Senhor localiza, portanto, o ato de votar, faz de $E U$ um eleitor e, ainda, constrói um engajamento por parte daquele que vota no voto exercido. Eu votei pelo Senhor, nessa contextualização, diz que eu me engajei nessa escolha, eu sou responsável pela escolha feita. Há localização do ato de votar e uma completa requalificação do estatuto do eu que vota, o que explica a determinação qualitativa e quantitativa introduzidas por Y.

Vale dizer que (A) e (B) apresentam um custo enunciativo significativo, não sendo facilmente observados. Em ambos, Eu votei pelo Senhor aproxima-se de Eu votei em seu lugar, com a diferença de que $\mathrm{Y}$ apreende a relação entre EUNVOTAR sob uma ótica específica: em (A), o meu voto, em que consta meu nome, diz o voto de outro, como se $E U$ tivesse "vendido" o voto; em (B), o meu voto nunca é meu por se fazer por meio de outro nome (e pouco importa se o voto exercido dá a ver a minha escolha ou a escolha de outro: é sempre evidenciado o nome de outro).

É interessante constatar que não se pode ter, em lugar de Y, um termo que, em si, seja subdeterminado, como, por exemplo, prefeito. Não se pode dizer *Eu votei POR prefeito, pois, nessa sequência, prefeito, ao evocar uma função social, não pode determinar uma escolha da parte de um eu que vota. Essa restrição desaparece com a presença do artigo definido $E$ u votei $P E L O$ prefeito, que remete a um indivíduo que ocupa a função de prefeito.

Consideremos agora o exemplo (17) Claudia deu aulas POR mim, em que POR Y requalifica a relação existente entre Claudia e aulas. Se Claudia pode ser apreendida como alguém que dá aulas, ora ela as assume sendo motivada por alguém (mim), ora ela não é mais a responsável pelas aulas que dá. Essa sequência dá lugar a três contextualizações, conforme as determinações introduzidas por (Y) mim:

A. Claudia deu aulas e as aulas dadas foram organizadas e elaboradas por mim. Reencontramos aqui a ideia de um sujeito que nada mais é do que um simples portavoz, no sentido em que não é nem o autor do conteúdo das aulas, nem o responsável por sua organização: Claudia apenas reproduziu as aulas concebidas por outro. Em outras palavras, as aulas foram dadas e isso supõe que alguém as preparou; na origem dessa preparação, temos (Y) mim e não Claudia. O ato de dar aulas não é capaz de apreender Claudia como o verdadeiro autor do curso dado. Se Y introduz 
determinação qualitativa, é por fazer de Claudia um suporte para que as aulas se manifestem.

B. Claudia deu aulas em um curso que está sob minha responsabilidade. O nome que consta na matriz curricular referente a um dado curso é o meu, mas foi Claudia quem deu as aulas que o constituem. Na origem da preparação das aulas, temos Claudia, mas eu continuo sendo o responsável oficial pelo curso. Coloca-se em evidência o fato de os cursos terem sido dados, mas não o de Claudia como o autor dos cursos, uma vez que o nome do responsável pelo curso sou eu.

C. Claudia deu um curso que, a priori, seria meu. Eu era o responsável pelo curso e Claudia o assumiu, sendo seu, a partir de então, o curso que antes estava sob minha responsabilidade. Temos aqui uma interpretação que tende a se aproximar de uma substituição, exceto pelo fato de que o ato de dar aulas tem, em sua motivação, o outro: Claudia fez isso, por exemplo, porque eu não podia assumi-lo, porque ela tem consideração por mim etc. Nesse caso, o ato de dar aulas faz de Claudia aquele que é tido efetivamente por seu responsável.

Por fim, pode-se dizer que, se em (C), temos alguém que, ao mesmo tempo, faz algo (vota, dá aulas) e é visto como o responsável pelo voto exercido ou pelas aulas dadas, em (A) e (B) o sujeito não é mais apreendido nem como eleitor, nem como autor dos cursos: em A, torna-se porta-voz de outro, sendo privado, diríamos, de agentividade; em (B), é privado de legitimidade, pois seu ato aparece sob o nome de outro.

\section{ALGUMAS CONSIDERAÇÕES SOBRE USOS EM QUE POR INTRODUZ PREDICATIVO}

O estudo proposto fundamenta-se em um conjunto de hipóteses que foram elaboradas por Franckel e Paillard (2007) e que têm sido postas à prova desde então. No que se refere mais especificamente aos usos intraproposicionais, tais hipóteses sustentam que:

\footnotetext{
1) a preposição tem uma função predicativa, inclusive em casos em que $X$ não corresponde a um termo diretamente identificado no enunciado; 2) quando a preposição está relacionada à recção verbal, sua função não se reduz à introdução de um argumento do verbo; 3 ) a preposição conserva a sua semântica em todos os empregos. Nesta perspectiva, a interação entre $V$ e Preposição decorre de uma combinatória entre dois predicados (o verbo e a preposição), com graus diferentes de intricação" (FRANCKEL; PAILLARD, 2007, p. 18-19, grifos nossos).
}

A complexidade dessa combinatória, questão observada desde o início deste trabalho, mostra-se em toda a sua extensão em exemplos em que, para um mesmo verbo seguido de uma mesma preposição, há interpretações variadas. Os exemplos mencionados 
no item anterior são significativos no que se refere ao modo como ocorrem tais intricações, visto que, neles, em particular, a variação é observada no âmbito de uma mesma sequência.

Uma construção como passar por seria igualmente representativa dessas intricações, visto que, além de Passamos por Porto Seguro já analisado, temos, ainda, passar seguido de POR em um conjunto extremamente variado de exemplos: Ele passou por um fraco, por uma cirurgia difícil, por provações, por momentos deliciosos, por minha existência etc. Dada a própria amplitude do funcionamento de um verbo como passar, só o conhecimento do esquema operatório ${ }^{16}$ que lhe é característico permite entender em profundidade as diferentes intricações entre parâmetros específicos de seu funcionamento e os que descrevem a preposição. Em outras palavras, só ambas as descrições permitem especificar qual elemento referente ao esquema operatório do verbo corresponde ao $\mathrm{X}$ no funcionamento preposicional.

Não sendo possível, neste trabalho, apresentar o esquema operatório do verbo passar $^{17}$, diríamos apenas que, em exemplos como (18) Ele passou POR um fraco, temos um funcionamento verbal que se aproxima, por outro viés, de construções como passar medo, raiva, dor, vontade; João está passado; o tempo passa etc.

Com efeito, temos, em passar medo, raiva, dor, vontade um conjunto de termos que, em tais construções, evocam sentimentos ou desejos que se apoderam de alguém; ou então, temos João como tomado por algo que o consome (por exemplo, a perda de alguém) e que deve ser recuperado na interpretação do enunciado. É interessante observar a exterioridade do sentimento em relação a quem o experimenta: da mesma forma que em passar frio ou passar calor, temos frio e calor como termos que evocam fenômenos externos ao sujeito experienciador, em passar medo, passar raiva etc., temos a representação de sentimentos que também podem ser considerados externos, não porque oriundos de algum fenômeno físico (como no caso de frio ou calor), mas porque entendidos como algo que se apropria do sujeito independentemente de sua vontade (ou são desencadeados por fatores que escapam ao sujeito). Daí a dificuldade de se dizer passar alegria em construção análoga a passar medo, já que alegria dificilmente é vista como algo que se apodera de nós. Já em o tempo passa, tempo é apreendido como algo ininterrupto, cujos efeitos se atualizam indistintamente em algo (corpo, vida, alguém etc.), algo que é tomado pelo tempo: tempo é representado como perceptível a partir dos efeitos que provoca $^{18}$. Mais uma vez, a atualização é circunstancial, ainda que, no caso de tempo, possa se ter a impressão de eternidade (característica vinculada ao próprio termo tempo, e não a passar). Nestes exemplos, fora da atualização de medo, raiva, dor etc. por ele, ou dos efeitos do tempo em alguém, o que se têm é a própria ausência medo, raiva, dor, efeitos do tempo.

De certa maneira, POR, em (18) Ele passou POR um fraco, faz com que (Y) um fraco seja delimitado, não como um indivíduo, mas como um conjunto de propriedades (as

16 Esse esquema, para verbos e nomes, é conhecido por forma esquemática (FE), que, vale notar, não reproduz a relação argumental do verbo. Ver DE VOGÜÉ, 2011a, 2011b, sobre tais questões. Ver ainda DE VOGÜÉ; CAMUS (2004) e ROMERO (2000, 2010) sobre o estudo dos processos de variação de unidades verbais.

17 Ver ROMERO, DEL RÉ (no prelo), sobre um primeiro estudo do funcionamento do verbo passar em PB. 18 No referido artigo, fazemos uma diferença entre esta contextualização de $O$ tempo passa e uma segunda, em que tempo remete ao passar das horas. Daí tratarmos, aqui, especificamente da primeira contextualização. 
propriedades que especificam o que seria um fraco) determinando o comportamento atualizado por ele. Dada a atualização circunstancial característica do verbo passar e o fato de ser POR que define o conjunto de propriedades que vai apreender o comportamento sob uma ótica específica, constroi-se a representação de que ele dá a ver um fraco, o que não significa que ele o seja, e, o mais importante, constroi-se uma representação em que o próprio sujeito não tem domínio sobre a representação que desencadeia no outro. Isso explicaria o fato de que os verbos, nas construções em que POR é considerado como introduzindo predicativo, sejam muitas vezes relacionados ao campo semântico do julgamento: Ele me tem, me toma POR um fraco.

\section{CONCLUSÃO}

O estudo sistemático de usos da preposição POR contemplando a variedade de empregos que lhe são característicos buscou mostrar não apenas o fato de ser possível analisá-la sob a ótica de uma abordagem de funcionamento unitária, mas de ser possível compreender o modo como seu semantismo característico - sua identidade semântica - se faz presente e contribui para a produção dos sentidos dos enunciados aos quais se integra.

O objetivo maior foi justamente o de apontar para a sua regularidade de funcionamento no que se refere à organização enunciativa. Por outro lado, a análise ainda traz inúmeros desafios, um deles sendo, justamente, o de contribuir para uma melhor compreensão dos diferentes graus de intrincação entre um dado verbo e a preposição, o que, por fim, ultrapassa a própria descrição da semântica da preposição por fazer com que um conjunto de aspectos oriundos da sintaxe sejam necessariamente repensados.

\section{REFERÊNCIAS}

DE VOGÜÉ, Sarah; CAMUS, Rémi (Org.). Variation sémantique et syntaxique des unités lexicales : études de six verbes français. LINX 50. Nanterre: Université de Paris X, 2004.

DE VOGÜÉ, Sarah. Os princípios organizadores da variedade das construções verbais. Tradução de Márcia Romero e Helena Valentim. ReVEL, v. 9, n. 16, 2011 a.

A la recherche des paramètres de l'élaboration du sens au sein des énoncés.

CORELA. Poitiers: Université de Poitiers, p. 1-29, 2011 b. 
DE VOGÜÉ, Sarah; FRANCKEL, Jean-Jacques; PAILLARD, Denis. Linguagem $e$ enunciação: representação, referenciação e regulação. Organização de textos e de tradução por Márcia Romero e Milenne Biasotto-Holmo. São Paulo: Contexto, 2011.

FRANCKEL, Jean-Jacques; PAILLARD, Denis. Considérations sur l'antéposition des syntagmes prépositionnels. In: GUIMIER, C. (Dir.). La thématisation dans les langues. Actes du Colloque de Caen. Paris: Peter Lang, p.277-295, 1997.

De la couleur des prépositions dans leurs emplois fonctionnels. Modèles linguistiques, tome XXVII-2, v. 54. Editions des Dauphins, p. 51-66, 2006.

. Grammaire des prépositions. Tomo 1. Paris: Éditions Ophrys, 2007.

ILARI, Rodolfo; NEVES, Maria Helena de Moura (Org.). Gramática do português culto falado no Brasil: classes de palavras e processos de construção. Tomo 2, Campinas, São Paulo: Editora da UNICAMP, 2008.

JALENQUES, Pierre. Un exemple d'interaction morphologiesyntaxe-sémantique: les contraintes sur les procès transitionnels au passif périphrastique. Liens linguistiques. Berne: Peter Lang, p. 409425, 2010.

NEVES, Maria Helena de Moura. Gramática de usos do português. São Paulo: Editora UNESP, 2000.

PAILLARD, Denis. A propos de la préposition avec. LINX. Paris: Université Paris Ouest (no prelo).

ROMERO-LOPES, Márcia Cristina (2000) Processos enunciativos de variação semântica e identidade lexical: a polissemia redimensionada. Tese de Doutorado, Faculdade de Filosofia, Letras e Ciências Humanas, Universidade de São Paulo.

ROMERO, Márcia. Um possível diálogo entre a Teoria das Operações Enunciativas e a Aquisição: identidade semântica e produtividade discursiva. Alfa, São Paulo, n. 54, v. 2, p.475-503, 2010.

Le fonctionnement sémantique de la préposition por en portugais brésilien. Faits de Langues, Les Cahiers numéro 3. Paris: Ophrys, p. 209-232, 2011.

ROMERO, Márcia; DEL RÉ, Alessandra. A aquisição do léxico entre a invariância e a variação. In: O valor de Saussure. LIMA, Maria Hozanete Alves de; OLIVEIRA, Eduardo Calil, Rio Grande do Norte: UFRN, no prelo.

ROMERO, Márcia; VILELA, Thatiana Ribeiro. O uso interproposicional de POR em uma descrição unitária de funcionamento da preposição. SEMINÁRIO ENUNCIAÇÃO E MATERIALIDADE LINGUÍSTICA, 1, 2012, Belo Horizonte. Anais: UFMG, no prelo. 
Recebido em: 14/11/2012

Aceito em: 01/04/2013

Versão revisada recebida em: 10/05/2013

Publicado em: 14/06/2013

\title{
ENUNCIATIVE PROCESSES AND SEMANTIC IDENTITY OF THE PREPOSITION POR
}

\begin{abstract}
This paper aims to examine the wide range of uses of the preposition POR (in Brazilian Portuguese) within the scope of a unitary approach regarding its function as a semantic unit. Our interest particularly concerns the semantic contributions of the aforementioned preposition with the attempt to highlight the modes of utterances within all possible types of contexts in which the preposition POR can occur. After shedding some light on the obstacles that hinder the establishment of a consistent categorization that leads to a semantic identity of the preposition POR, we come to propose an analysis inspired by the works of Franckel \& Paillard (2007) whose main ideas are, on the one hand, to re-establish what its different uses might have in common and, on the other hand, to understand the way variation takes place.
\end{abstract}

KEYWORDS: semantics of prepositions; Brazilian Portuguese; semantic identity. 